\title{
Implications of Integrating Women into USMC Infantry
}

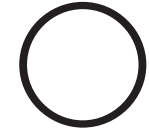

n January 24, 2013, the Secretary of Defense and the Chairman of the Joint Chiefs of Staff announced the rescission of the 1994 Direct Ground Combat Definition and Assignment Rule (DGCDAR). The effect of this decision will be consideration of opening previously closed occupations-including those within the United States Marine Corps (USMC) infantry-to women who can meet validated occupation-specific, gender-neutral standards of performance. In response to this change in policy, the Marine Corps Combat Development Command asked RAND to help identify issues that may arise if women are integrated into the Marine Corps infantry, describe efforts that have been successful in addressing these issues in the past, and estimate the potential costs associated with integration.

To do so, RAND researchers undertook four tasks: review of research on integration of women into ground combat and other physically demanding occupations, interviews with representatives of organizations in physically demanding occupations, estimate of the costs of potential initiatives to promote successful gender integration, and development of an approach for monitoring implementation of gender integration of the infantry. This brief summarizes the researchers' findings on cohesion, "critical mass," lessons learned from the experiences of foreign militaries as well as from U.S. fire and police departments, costs associated with integration, development of a monitoring framework, and cross-cutting implications and recommendations.

\section{Cohesion}

While cohesion can affect group performance, performance can affect cohesion even more. The effect of gender integration on the cohesion of traditionally male groups depends on the culture of the group: Groups more hostile to women experience lower cohesion after gender integration than do groups less hostile toward women. Gender integration is therefore more likely to negatively affect cohesion when the social context of the unit creates a hostile environment for women.

A variety of efforts can mitigate whatever detrimental effects integration of women would have on male-dominated groups. Good leadership is key to increasing the acceptance of women. Leaders who treat women and men fairly, provide support for women, and emphasize the good of the group

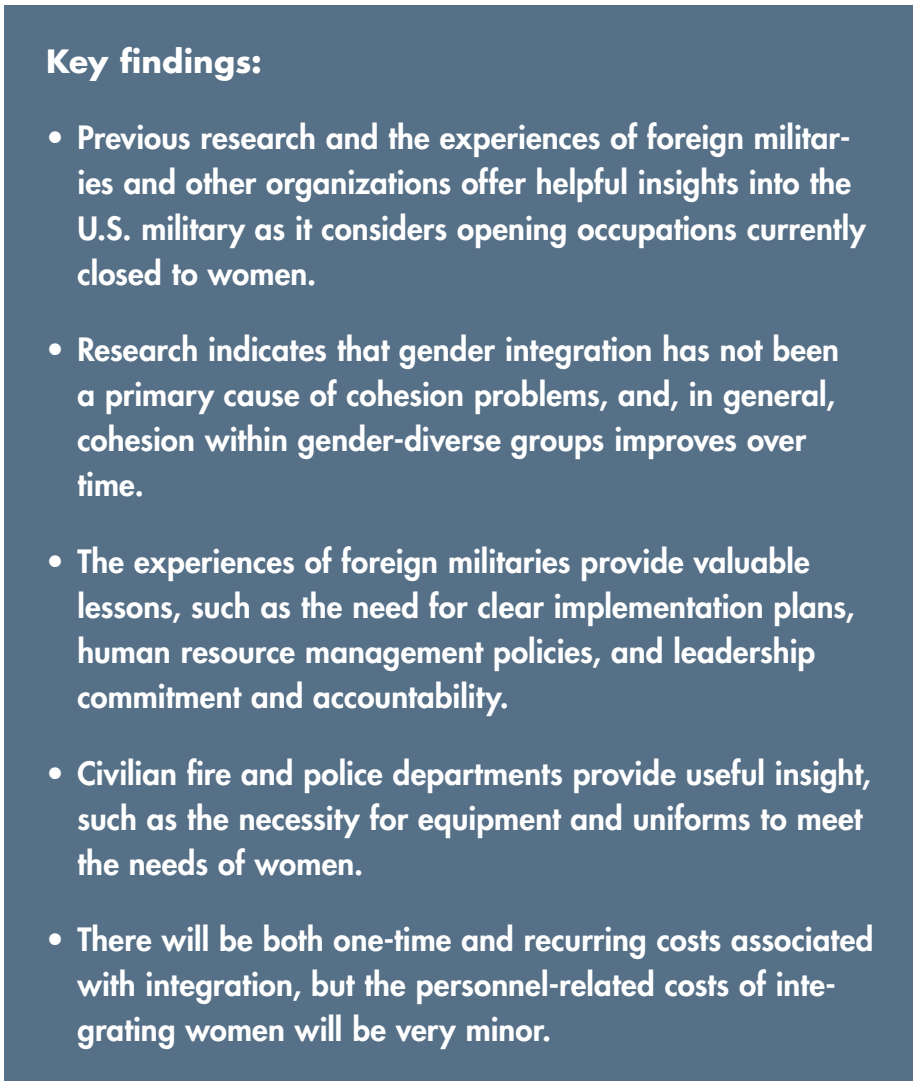

help foster cohesion where women are fully integrated into group life. The USMC can also implement cohesion-building activities. Cohesion in gender-integrated groups is likely to increase over time as groups work together and develop a shared sense of identity.

\section{Critical Mass}

The concept of "critical mass" suggests that the experiences of women in a male-dominated group change as the number of women in the group increases. The USMC asked RAND to identify whether there is a critical-mass threshold or minimum number of women in a given unit that would facilitate their success. Findings from previous research, as well as from foreign militaries, show little consensus on what actually constitutes a "critical mass." The experiences of foreign militaries also suggest that setting a single, rigid threshold or proportion may be difficult and counterproductive. 
Nevertheless, experiences of foreign militaries do suggest that assigning women in groups of a sufficient size does increase their satisfaction and success, particularly in occupations that have small numbers of women in them. Evidence also indicates that women generally perform better in groups where individuals are not the only woman in a group. While the experiences of foreign militaries do not point to a precise threshold or standard, the Marine Corps may wish to consider experimenting with various gender mixes for infantry units to determine optimal proportions in different units.

\section{Lessons Learned from Foreign Militaries}

RAND analysis of the experiences of foreign militaries in gender integration suggests four general observations. These include the importance of leadership commitment and accountability, issues related to implementation, the need for human resource management strategies, and issues related to physical standards.

Regarding leadership commitment and accountability, senior leaders and key stakeholders note that, without such commitment and visible involvement, progress on integration is difficult or impossible to achieve. Integration must be supported by legal and policy changes, which senior leaders are uniquely positioned to implement and enforce. RAND analysis suggests that countries with a high institutional commitment to integration have achieved at least a moderate degree of success and that most such countries have achieved a high degree of success (see the table).

Foreign military leaders and researchers noted that phased integration may support progress, as it allows integration to occur gradually alongside training. It also facilitates frequent status checks and corrections as needed. Having a clear implementation plan is another key element of successful integration programs.

Human resource management policies must also support integration. In particular, countries that have been relatively more effective at integrating women into combat-arms operations have employed targeted recruitment and retention policies that attract women into such occupations and keep them there. These might include flexible workplace policies and child-care resources; well-defined, updated, and clearly communicated sexual harassment policies; and procedures to ensure that women receive equal training and promotion opportunities.

The experiences of other countries suggest that genderneutral physical standards should be frequently monitored and revised. Gender-neutral standards may reduce barriers to integration because they help establish an equal foundation among all recruits. Several countries have sped the integration process by providing additional training for female recruits prior to or after enlistment.

\section{Lessons Learned from U.S. Police and Fire Departments}

The researchers identified fire departments as the domestic nonmilitary organizations most likely to offer insights into the Marine Corps on infantry gender integration, and police departments as the second-most likely to do so. Their analysis of these organizations had four principal findings for gender integration:

- Equipment and uniforms must meet the needs of women.

- Small-unit dynamics and discipline must be closely monitored.

- Integration challenges change and mature over time.

- Integrating organizations should remain open to external perspectives that can better facilitate the integration process.

While no civilian organization is directly comparable to the USMC, the experiences of civilian organizations indicate that integration is a process in which issues change with the career progression of women in new occupations. Initially after integration, issues and challenges tend to focus on recruiting and hiring. As time progresses, issues and challenges related to promotion and retention arise. By proactively monitoring these issues that change over time, the USMC can identify and address them quickly.

\section{Assessment of Integration Success and Institutional Commitment in Foreign Militaries}

\begin{tabular}{|c|c|c|c|}
\hline \multirow[b]{2}{*}{ Integration Success } & \multicolumn{3}{|c|}{ Institutional Commitment } \\
\hline & High & Moderate & Low \\
\hline High & $\begin{array}{l}\text { Australia, Canada, Denmark, Norway, } \\
\text { Sweden, Israel }\end{array}$ & & \\
\hline Moderate & $\begin{array}{l}\text { Germany, Netherlands, New Zealand, } \\
\text { South Africa }\end{array}$ & $\begin{array}{l}\text { Albania, Belgium, Finland, Hungary, } \\
\text { Italy, Romania, Slovenia, Spain }\end{array}$ & France \\
\hline Low & & $\begin{array}{l}\text { Croatia, Greece, Latvia, Lithuania, } \\
\text { Mexico, Russia }\end{array}$ & Poland, Portugal, Slovakia, Ukraine \\
\hline
\end{tabular}




\section{Costs Associated with Integration}

To estimate costs associated with integrating women into the USMC infantry, the researchers divided costs into two categories: one-time costs, such as costs for research and development and those associated with necessary changes to equipment or facilities, and recurring costs, such as those resulting should women complete training at a lower rate or spend fewer months in the military, as well as those associated with gender training, gender advisers, or other specific resources for integration.

Supporting the researchers' estimates, U.S. military experiences in opening previously closed occupations to women and the experiences of foreign militaries suggest that the number of women initially entering the infantry will be modest, and the increase in representation slow. Opening the infantry to women will have some costs, assuming women have higher levels of attrition during training and fewer months of service than men, but the researchers' models estimate that these would be only about $0.1 \%$ of the overall recruiting budget. The Marine Corps can make up any shortfall in the infantry effectively through increased recruitment or retention. Retaining women who do not successfully complete infantry training in another military occupational specialty offers one way to minimize costs, just as retaining men who do not complete training also has significant cost implications.

\section{Developing a Monitoring Framework}

The researchers developed a framework to assist the USMC in monitoring gender integration. This framework has a planning phase (before the decision to integrate has been made) and a Phase One (up to five years after integration, at which point the USMC should conduct a comprehensive evaluation of the integration process to reevaluate monitoring priorities).

The monitoring framework identifies (1) the types of issues to be monitored over time ("what are you measuring?"), (2) metrics ("how are you measuring progress, and what information do you need?"), and (3) methods ("how are you collecting the information you need to measure progress-administrative data, surveys?"). The goal of this monitoring framework is to identify broad types of data systems and data collection methods that the USMC could use to help monitor various integration issues. This type of monitoring will also facilitate the quick identification of integration challenges so that they can be addressed in a timely manner.

Monitoring something as sensitive and important as gender integration in combat roles will require constant vigilance. A monitoring plan must have long-term and deliberate methods for measuring progress, including personnel policy and collection of data or statistics, and must include strategies to measure institutional and cultural change over time.

\section{Cross-Cutting Implications}

Altogether, the research identifies seven areas as particularly relevant to implementing gender integration.

First, leadership is key to integration success. It is key to setting the tone for the integration process and ensuring that cohesion is not negatively affected. Clear communication can also help facilitate integration by clarifying goals.

Second, development of a detailed implementation plan is a common element of successful integration efforts. Well-designed implementation plans that assign responsibility, identify risks, and outline mitigation strategies are particularly effective in streamlining the integration process. Without accountability for implementation, the integration process can stagnate or atrophy.

Third, oversight mechanisms can help set and define requirements for longer-term progress. Oversight will require data collection, which in turn can require long lead times and be expensive. As the Marine Corps begins implementation planning, it should consider the structure of oversight mechanisms that it could establish. External oversight can also help build trust, transparency, and accountability.

Fourth, gender integration is a long process, which will require consideration of long-term career-progression issues. As noted, over time challenges are likely to shift from issues such as recruiting and hiring to promotion and retention. Given the long-term retention issues foreign militaries have had with women in combat-arms occupations, the Marine Corps may wish to consider career-progression issues from the onset of implementation.

Fifth, the Marine Corps will need to develop integration strategies that best suit the Marine Corps through experimentation. In developing its own programs over time, the Marine Corps should link experimentation to data collection, analysis, and evaluation. These data, analyses, and evaluations are the building blocks for monitoring. They can also help to refine the implementation plan and associated policies.

Sixth, the Marine Corps should monitor integration progress over time. A strong monitoring plan relies on robust data systems for measuring integration progress. As the Marine Corps plans for implementation, it should consider which data systems are already in place to collect appropriate data and whether any new data systems are necessary.

Seventh, and finally, the Marine Corps will need to manage both internal and external expectations and ensure that the planning process for integration is flexible enough to accommodate learning and adjustments. Both proponents and opponents of integration will have particular expectations about 
how the Marine Corps should handle the decision to integrate the infantry, as well as how to implement any changes. To maximize the chances of success, the Marine Corps will need to base its decision and implementation strategy on empirical data. This will allow it to set realistic goals and to counter pressure from proponents and opponents of integration.
The Marine Corps should also set realistic goals for success based on input from various analyses it has under way. Putting systems in place to collect appropriate data throughout the integration process will help build evidence for further improvements to integration.
This research brief describes work done in the RAND National Defense Research Institute and documented in Implications of Integrating Women into the Marine Corps Infantry, by Agnes Gereben Schaefer, Jennie W. Wenger, Jennifer Kavanagh, Jonathan P. Wong, Gillian S. Oak, Thomas E. Trail, and Todd Nichols, RR-1103-USMC (available at www.rand.org/t/RR1103), 2015. To view this brief online, visit www.rand.org/t/RB9878. The RAND Corporation is a research organization that develops solutions to public policy challenges to help make communities throughout the world safer and more secure, healthier and more prosperous. RAND is nonprofit, nonpartisan, and committed to the public interest. RAND's publications do not necessarily reflect the opinions of its research clients and sponsors. RAND ${ }^{\circledR}$ is a registered trademark. ๑ RAND 2015

Limited Print and Electronic Distribution Rights: This document and trademark(s) contained herein are protected by law. This representation of RAND intellectual property is provided for noncommercial use only. Unauthorized posting of this publication online is prohibited. Permission is given to duplicate this document for personal use only, as long as it is unaltered and complete. Permission is required from RAND to reproduce, or reuse in another form, any of our research documents for commercial use. For information on reprint and linking permissions, please visit www.rand.org/pubs/permissions.html. 